\title{
Electrochemical Process Concerning the Decomposition of Sodium Amalgam*
}

\author{
Fumio HINE**, Masaru OKAdA**, Shiro YoshizAwA**, and Shinzo OKADA**
}

The decomposition of amalgam, which is one of the most important processes in amalgam method of alkaline industry, is considered.

The chemical reaction in the decomposer of amalgam, i.e.,

$$
\mathrm{Na}-\text { Amalgam }+\mathrm{H}_{2} \mathrm{O}=\mathrm{NaOH}+\frac{1}{2} \mathrm{H}_{2}
$$

consists of two electrochemical processes,

$\mathrm{Na}-\mathrm{Amalgam} \rightarrow \mathrm{Na}^{+}-\Theta$ at amalgam surface (anodic reaction),

and

$$
\mathrm{H}_{2}+\Theta \rightarrow \mathrm{OH}^{-}+\frac{1}{2} \mathrm{H}_{2} \text { at graphite surface (cathodic reaction). }
$$

If the anodic dissolution of sodium from amalgam into caustic soda and the cathodic hydrogen electrode reaction in the decomposer are individually observed, the overall decomposition process of amalgam can be understood in detail. These anodic and cathodic polarization characteristics are given in Fig. 1, in which $\eta_{a}{ }^{0}$ and $\eta_{c}{ }^{0}$ are the equilibrium electrode potentials of amalgam and hydrogen, respectively.

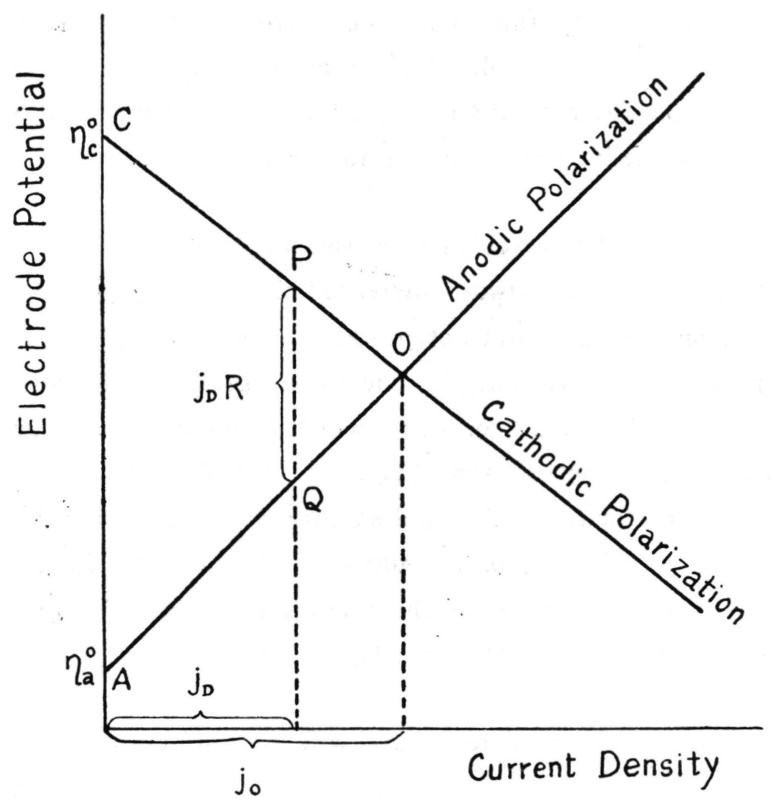

Fig. 1 Polarization Characteristics for Amalgam-decomposition.

For example, if the amalgam is kept in contact with the graphite, local current begins to flow between them due to the electromotive force, $\eta_{a}{ }^{0}-\eta_{c}{ }^{0}$. However, the electrode potentials of both surfaces undergo changes toward the value at the cross point $\mathrm{O}$ along two polarization curves, $\mathrm{AO}$ and $\mathrm{CO}$, respectively, while the local current increases. Thus, if the resistance of contact of electrodes and that of electrolyte is assumed to be ignored the anodic and cathodic potentials become equal with each other, at the point $\mathrm{O}$ and the current jo, which is considered to be limiting or maximum,

* Studies on Amalgam Decomposition of Alkaline Industry (Part I)

** Department of Industrial Chemistry, Kyoto University, Yoshida, Kyoto.

The original written in Japanese can be seen in J. Electrochem. Soc. Japan 27, 134 (1959) 
flows between such a short-circuited couple. In practice, however, there exists potential difference shown as $\mathrm{PQ}$ in the figure between both electrodes due to the ohmic resistance of electrolyte and the contact resistance, and so the decomposition current may be $\mathbf{j}_{\mathrm{D}}\left(<\mathbf{j}_{0}\right)$. Then, the decomposition yield, $w$, is represented by the well-known Faraday's Law, if current efficiency is assumed to be $100 \%$,

$$
w=z j_{0} t
$$

where $\mathrm{z}$ is the electrochemical equivalent and $t$ the duration of the electrolysis.

1. Electromotive force Now, the electromotive force of local cell

$\mathrm{Na}-\mathrm{Hg}(\mathrm{Y})|\mathrm{NaOHaq.}(\mathrm{X})| \mathrm{H}_{2}-$ graphite

is represented as follows:

$$
E=E_{0}+\frac{R T}{F} \log \frac{Y W}{X}
$$

where $W$ is the activity of water in the caustic soda solution.

2. Resistances for processes at amalgam surface The interface between amalgam and caustic soda is profiled in Fig. 2. The material balance may be represented as follows:

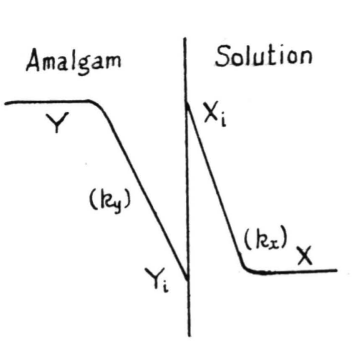

$$
\begin{aligned}
\frac{j}{F} & =k_{y}\left(Y-Y_{i}\right) \text { diffusion process in amalgam } \\
& =k_{a}\left[Y_{i} e^{\frac{\alpha F \pi_{a}}{R T}}-\frac{Y}{X} X_{i} e^{\left.-\frac{\alpha^{\prime} F \pi_{a}}{R T}\right]} \text { activation process }\right\} \cdots \\
& =k_{x}\left(X_{i}-X\right) \text { diffusion process in caustic soda } \\
& =\frac{Y\left[e^{\frac{\alpha F \pi_{a}}{R T}}-e^{\left.-\frac{\alpha^{\prime} F \pi_{a}}{R T}\right]}\right.}{\frac{e^{\frac{\alpha F \pi a}{R T}}}{k_{y}}+\frac{1}{k_{a}}+\frac{Y}{X} \frac{e^{-\frac{\alpha F \pi a}{R T}}}{k_{x}}}
\end{aligned}
$$

Fig. 2 Diffusion of Reactant

Eq. (6) may be approximated as follows:

(i) if the diffusion process in amalgam is the ratedetermining step :

$$
\frac{j}{F}=k_{y} Y\left[1-e^{-\frac{F \pi_{a}}{R T}}\right]
$$

(ii) if the activation process is the rate-determining step :

$$
\frac{j}{F}=k_{a} Y\left[e^{\frac{\alpha F \pi a}{R T}}-e^{-\frac{\alpha^{\prime} F \pi a}{R T}}\right]
$$

(iii) if the diffusion process in solution is the rate-determining step :

$$
\frac{j}{F}=k_{x} X\left[e^{\frac{F \pi a}{R T}}-1\right]
$$

Fig. 3 shows a vessel used for anode, and the empirical conditions are as follows:

concentration of amalgam: $0.1-0.3 \%$ concentration of caustic soda : 20-70\% temperature : $40-80^{\circ} \mathrm{C}$

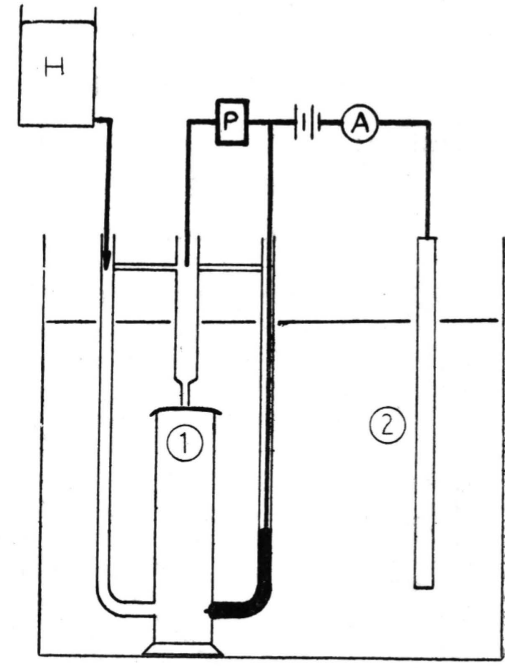

(1) amalgam pool

(2) anode H: Head tank

Fig. 3 Electrolytic Circuit.

Fig. 4 shows an example of the results, and Fig. 5 the characteristics of reference electrode.

\section{Hydrogen overpotential at contact materials (cathodic grids)}

The hydrogen overpotential at the surface of grids may be represented as

$$
\begin{gathered}
\pi c=\eta_{H^{0}}-\eta_{H}=a+b \log j \\
b=\frac{R T}{\alpha F}
\end{gathered}
$$




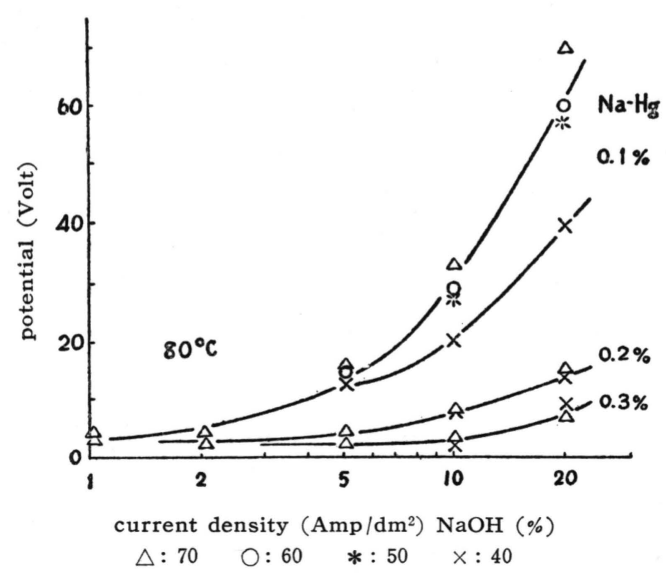

Fig. 4 Anodic Polarization Curve of Amalgam.

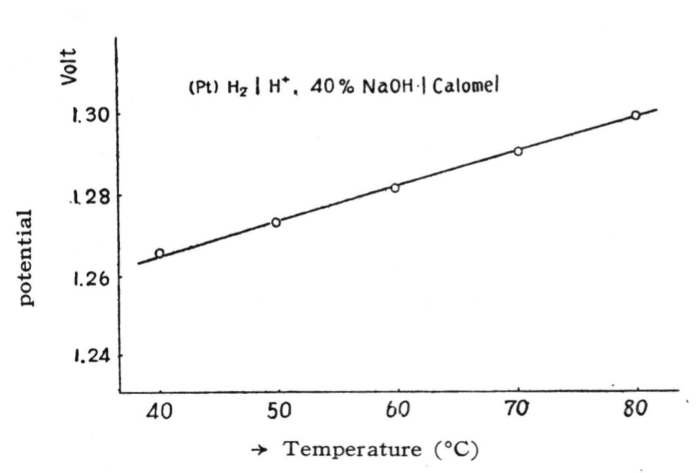

Fig. 5 Temperature Characteristics of Calomel Electrode in $40 \% \mathrm{NaOH}$.

or

$$
j=k \exp \left[\frac{U-\alpha F \pi_{c}}{R T}\right]
$$

The experimental is carried out under the following conditions:

contact materials (cathodic grids):

Graphite

Soft iron

Titanium ${ }^{1)}$

Graphite, treated with ferrous chloride solution ${ }^{2)}$

Graphite, sintered with iron powder ${ }^{3)}$

conditions :

concentration of caustic soda: $40-80 \%$

temperature : $40-80^{\circ} \mathrm{C}$

Figs. 6-10 show these results, and Table 1 gives the coefficients b and a of Tafel equation.

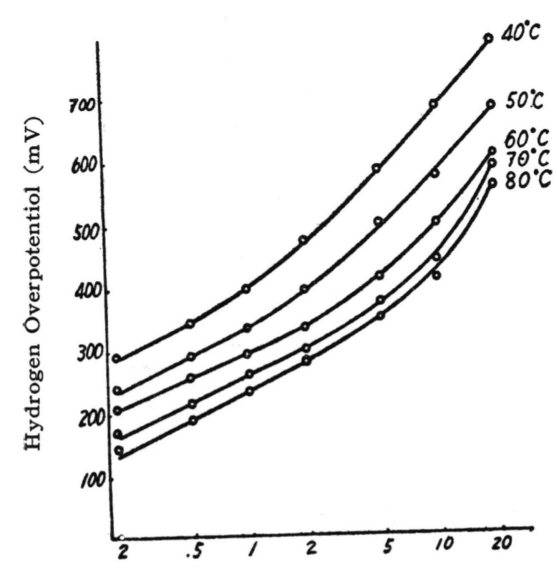

current density $\left(\mathrm{Amp} / \mathrm{dm}^{2}\right) \mathrm{NaOH} 40 \%$

Fig. 6 Hydrogen Overpotential on Graphite Cathode.

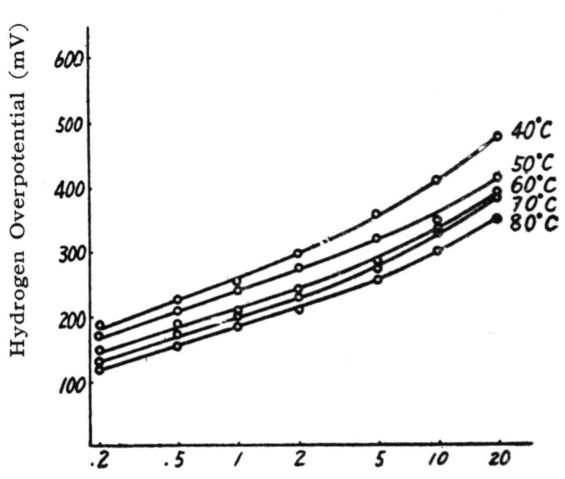

current density $\left(\mathrm{Amp} / \mathrm{dm}^{2}\right) \mathrm{NaOH} 40 \%$

Fig. 7 Hydrogen Overpotential on Steel Cathode. 


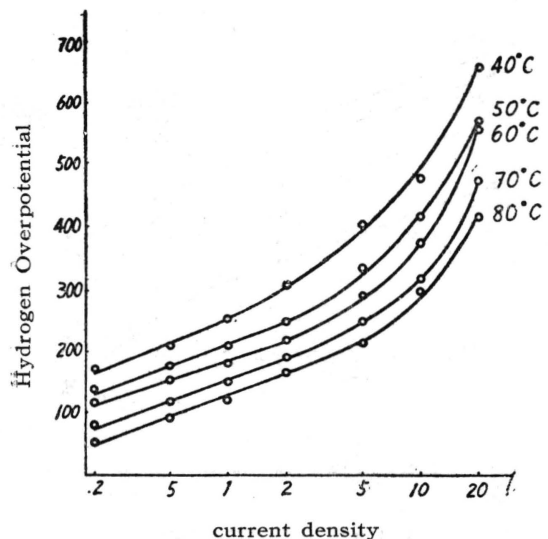

graphite, sintered with $5 \% \mathrm{Fe}, \mathrm{NaOH} 40 \%$

Fig. 8 Hydrogen Overpotential on Graphite, Sintered with $5 \% \mathrm{Fe}$.

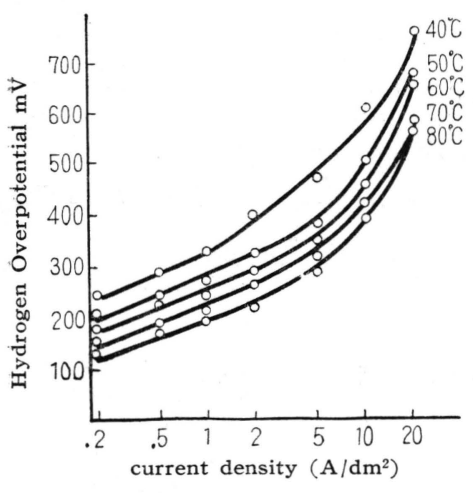

Fig. 9 Hydrogen Overpotential on Graphite, treated with $10 \%$ $\mathrm{FeCl}_{2}$.

The activation energy, $U$, can be calculated from the temperature characteristics of reaction rate given in Fig. 11.

The value of $U$ for three kinds of graphite are approximatelly equal to each other. Since the hydrogen overpotential of the two kinds of pretreated graphite are low, it is considered that these treated graphites have larger surface area.

Hydrogen overpotentials in caustic soda are constant for various concentrations of electrolyte as shown in Fig. 12, and the hydrogen overpotential may be experimentally represented as
Table 1

\begin{tabular}{l|c|c|c}
\hline \hline Materials & $2.303 \mathrm{~b}$ & $\alpha$ & $\mathrm{U}$ (Kcal) \\
\hline Soft Iron & 0.11 & 0.564 & 11.81 \\
Titanium & 0.10 & 0.620 & 16.07 \\
$\begin{array}{l}\text { Graphite } \\
\text { Graphite, } \\
\text { treated with } \\
\begin{array}{l}\text { 10\% FeCl } \\
\text { Graphite, } \\
\text { Sintered with } \\
5 \% \text { Fe }\end{array}\end{array}$ & 0.14 & 0.442 & 16.57 \\
\hline
\end{tabular}

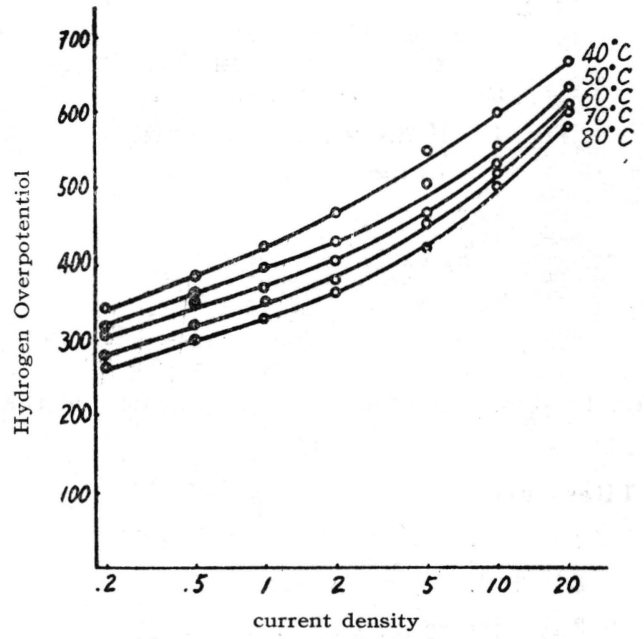

graphite, treated with $10 \% \mathrm{FeCl}_{2} \mathrm{NaOH} 40 \%$

Fig. 10 Hydrogen Overpotential on Titanium.

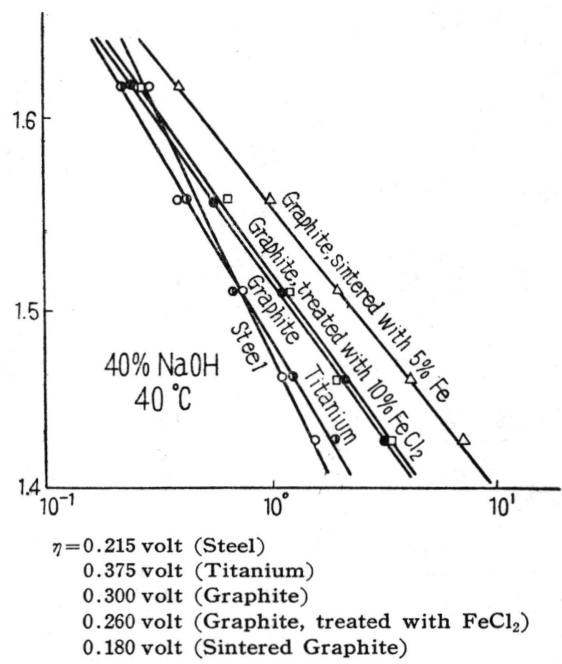

Fig. 11 Temperature Characteristics of Current Density on Cathode. 


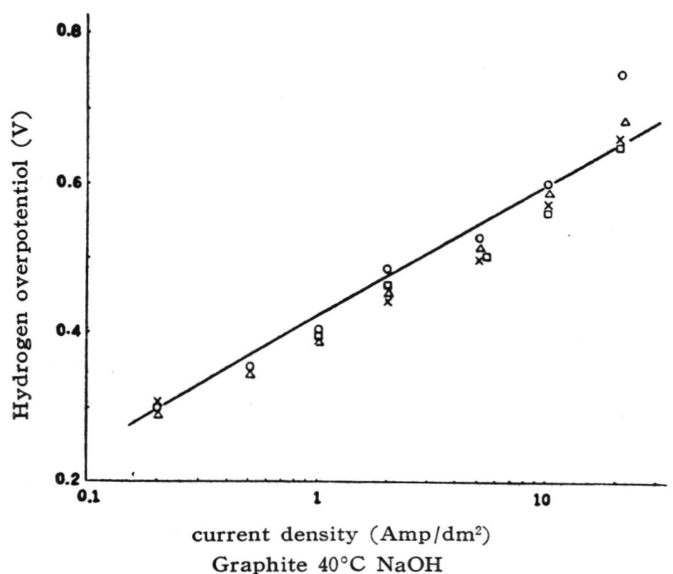

$\triangle 10 \% \quad \square 20 \% \quad \times 30 \% \quad \bigcirc 40 \%$

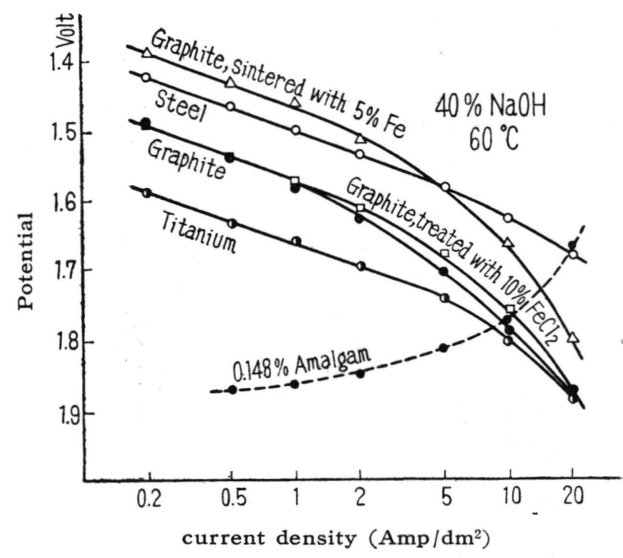

Fig. 13 Cathodic Polarization of Decomposers and Anodic Polarization of Amalgam

Fig. 12 Hydrogen Overpotential on Graphite

$$
\begin{aligned}
& \pi_{h}=\pi_{h}{ }^{0}+\frac{j}{k_{h}} \\
& \left.\pi_{h}{ }^{0}=0.43 \text { (Volt) and } \frac{1}{k_{h}}=0.013 \text { (Volt } / \mathrm{Amp} / \mathrm{dm}^{2}\right)
\end{aligned}
$$

Fig. 13 shows an example of the anodic and the cathodic polarization characteristics.

(Received June 13. 1958)

\section{Literature :}

(1) Pat. No. 224053 (1956. 7. 19)

(2) P.B. Report No.816, p. 46

(3) Yoshizawa, Ito: J. Chem. Soc. Japan (Ind. Chem. Section) 54, 620 (1951) 